\title{
Ultrastructure of the aetiological agent of systemic granuloma in goldfish
}

\author{
I. Paperna, S.-H. Kim \\ Department of Animal Sciences, Faculty of Agriculture of the Hebrew University of Jerusalem, Rehovot 76-100, Israel
}

\begin{abstract}
A fine structural investigation of the causative organisms of systemic granuloma in goldfish Carassius auratus revealed single-nucleate amoeboid organisms which were either intracellular, enclosed within a parasitophorous vacuole, or intercellular, embedded in an electron-dense matrix, presumably residues of defunct host cells. The nucleolemma-bound nucleus contained a large centrally positioned nucleolus. The cytoplasm contained ribosomal aggregates, endoplasmic reticulum and numerous adjunct thick-walled vesicles. Mitochondria were absent. Large cytoplasmic inclusions contained electron dense deposits. Additionally, cytoplasmic ribosome-rich bodies differentiated from the cytoplasm, segregating into an invagination of the organism's body wall and apparently were becoming confluent with the parasitophorous vacuole. The taxonomic and biological affinities of these organisms are discussed through comparison with similar Dermocystidium-like and amoeboid aetiological agents from fish.
\end{abstract}

KEY WORDS: Systemic granuloma - Goldfish Fine structure - Amoeboids · Dermocystidium-like organisms

\section{INTRODUCTION}

Systemic granuloma in goldfish Carassius auratus has been reported from North America (Voelker et al. 1977), Europe (Lom \& Dyková 1992, Steinhagen et al. 1993) and Israel (Landsberg \& Paperna 1992). Large grey nodular lesions occur first in the kidneys and then spread to the spleen, while the liver is only mildly affected. Histological examination has revealed granulomata with a necrotic core. In some fish, the granulomata are accompanied by numerous amoeboid organisms, in others, such organisms are few or entirely lacking (Landsberg \& Paperna 1992). These organisms have been named 'Dermocystidium-like' (Landsberg \& Paperna 1992), as have similar-looking organisms found to accompany systemic granulomatous conditions in salmonids (Hedrick et al. 1989). A few micrographs of the organisms that accompany goldfish granuloma have been presented by Voelker et al. (1977) and by Lom \& Dyková (1992), and a more detailed account has been presented by Steinhagen et al. (1993); all 3 reports suggested these organisms to be amoebae. In the present study further ultrastructural details of these organisms are presented and their taxonomic affinities in light of the present findings are discussed.

\section{MATERIALS AND METHODS}

Fish with granulomatous lesions were obtained from a farm in Israel rearing goldfish in earth ponds. Segments from the surface of kidney granulomatous nodules were fixed in Karnovski or in $2.5 \%$ cacodylatebuffered (0.1 M, pH 7.4) glutaraldehyde for $24 \mathrm{~h}$ at $4{ }^{\circ} \mathrm{C}$, rinsed repeatedly, and post-fixed in $1.0 \%$ osmium tetroxide in the same buffer for $1 \mathrm{~h}$. After rinsing in the same buffer, material was dehydrated in graded ethanols and embedded in Agar 100 medium (Agar Comp., UK). Thin sections cut on a Reichert 'Ultracut' ultratome with a diamond knife were stained on grids with uranyl acetate and lead citrate, and examined in a Jeol 100CX transmission electron microscope (TEM). Presence of the causative organisms was verified from either semithin sections stained with toluidine blue, or hematoxylin-eosin-stained histological sections pre- 
pared from another segment of the same tissue embedded in glycol-methacrylate (for methodology see Landsberg \& Paperna 1992)

\section{RESULTS}

Only once every few years do clinical conditions due to systemic granuloma and resulting mortalities in goldfish farms become high enough to cause concern among growers. Of the many samples of goldfish with clinical signs of systemic granuloma examined from 1982 to 1994 , only twice did processed material yield the amoeboid, or 'Dermocystidium-like', stages (Dorganisms): from fish examined in October 1984 and in early January 1995, both during severe outbreaks of kidney disease in farmed goldfish.

The D-organisms were detected at the surface of a large granulomatous nodule which already contained a large necrotic core. The organisms occurred within compressed layers of active epitheloid cells, either between cells, embedded in an electron-dense matrix containing many membranous residues (presumably remains of the defunct host cells) (Fig. 1), or intracellularly, enclosed tightly or loosely within a single membrane-bound parasitophorous vacuole (PV; Fig. 2). The inner adjoining layers of the host epitheloid cells were degenerating via hyalinization (Fig. 3). Some of the structures seen among the compressed hyalinized cells appeared to be residues of D-organisms (Figs. 3 \& 4). The host cell cytoplasm in most instances was of an entirely different texture and density than that of the D-organisms, and it contained vertebrate-type mitochondria (Fig. 5).

The organisms were bound by a single membrane. The cytoplasm contents were fine granular, rich in ribosomes, often in association with the endoplasmic reticulum (ER) (Fig. 5). A regular feature in the cytoplasm of all the organisms, irrespective of their state of organization, was a nucleus with a large central nucleolus with a conspicuous nucleolemma (Figs. 1, 2 \& 6), and numerous small, round, thick-walled vesicles, which seemed like a cross-section of microtubules; some were seen connected to an ER tubule (Fig. 5). There were no structures comparable to mitochondria. Most D-organisms displayed a variety of intracytoplasmic structures, some bearing evidence of definite organelles, others membrane-bound or free inclusions of homogeneous or textural (lobular, lamellar or membranous) electron-dense bodies, reminiscent of degenerating organelles or products of lysosomal action, resembling autolysosomes of encysting amoebae or degenerating cells (Figs. 2, 6 \& 7).

'Segregated' bodies-membrane-bound organelles enclosed inside a walled cytoplasmic inclusiondemonstrated variable consistencies, either fine granular with a few thick-walled vesicles as seen in the main cytoplasm (Figs. 2 \& 7). with peculiar rodlets (Fig. 6), or loaded with ribosomes (Fig. 7). These bodies differentiated from the cytoplasm, in the center of a large halo of dilute granular consistency (Fig. 8), and became enclosed in an extending invagination of the organism's body wall (Fig. 9). In this way they became confluent with the periphery of the organism (Fig. 10). Dense material accumulated in scattered aggregates inside the PV space (Fig. 2). In some of the D-organisms, the PV wall membrane duplicated and became deposited with a heavy electron-dense layer (Figs. 11 \& 12). Similar changes were seen in membranes enclosing the segregated bodies (Figs. 5 \& 7), whereas the loose cytoplasmic halo was absent.

\section{DISCUSSION}

All available TEM images of D-organisms from goldfish (Voelker et al. 1977, Lom \& Dyková 1992, Steinhagen et al. 1993, present study) are of nondivided forms. Nonetheless, they demonstrate similarities with dividing stages from carp (Kovacs-Gayer et al. 1986). Divided stages (rosettes) in goldfish have been seen only in light-microscopic preparations. From salmonids, TEM images of both nondivided and divided forms have been presented: the goldfish and carp material closely resembles stages reported from Atlantic salmon by McVicar \& Wooten (1980), whereas

Figs. 1 to 7 Fig. 1. D-organisms between cells, embedded in an electron-dense matrix. n: nucleus. $\times 10030$. Fig. 2. Intracellular organism with autolysosome-like inclusions (A) and 'segregated' bodies (B) within a parasitophorous vacuole, the latter containing electron-dense deposits (d), thick-walled vesicles (v) $\times 17000$. Fig. 3. Outer layer of the granuloma: epitheloid cells degenerating via hyalinization, with presumed residues of D-organisms (arrows) $\times 7905$. Fig. 4. Presumed residues of D-organism (bold arrows) with a seemingly defunct nucleus ( $\mathrm{n}$ ?) and 'segregated body' (B?). $\times 9775$. Fig. 5 . Enlarged view of D-organism, revealing a nucleolemma-bound nucleus with a central nucleolus (n), a ribosome-rich cytoplasm with ER (small arrows) connected to small thick-walled vesicles ( $\mathrm{v}$ and large arrows) and a 'segregated' body with thick-walled inclusion ( $B$ ) and an autolysosome-like inclusion (A). m: host-cell mitochondria. $\times 29282$. Fig. 6 . D-organism with 'segregated body' containing rodlets (B), enclosed in a halo of low density cytoplasm (arrow), autolysosome-like inclusion (A) and a nucleus (n) $\times 17000$. Fig. 7. Autolysosome-like inclusion (A) and 'segregated' bodies (B) with low and high density cytoplasm, enclosed within an inclusion lined with electron-dense deposits, also accumulating in the parasitophorous vacuole (arrows) $\times 24650$ 

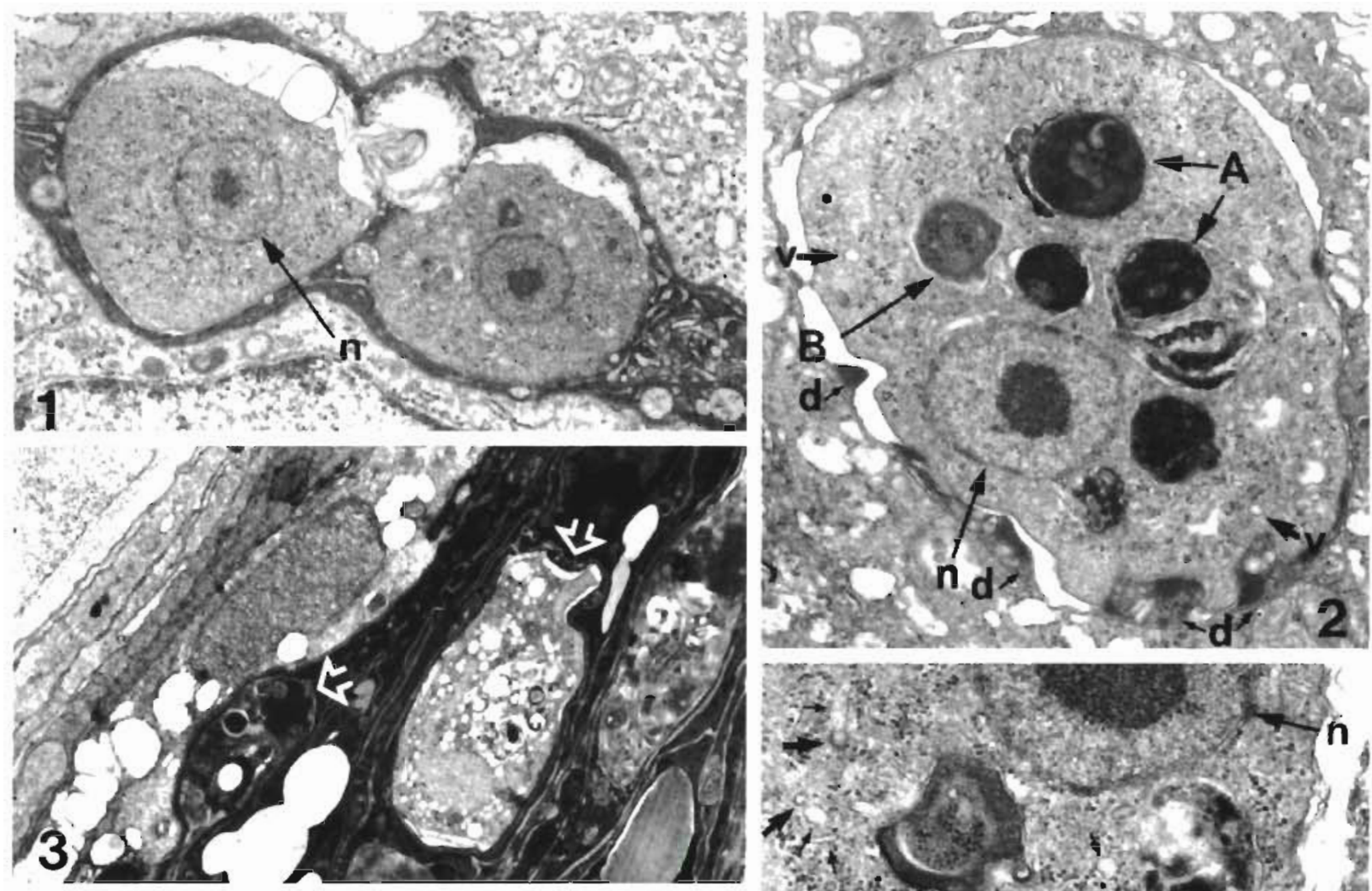

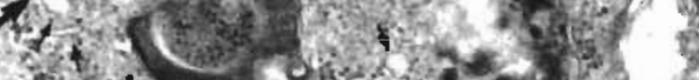

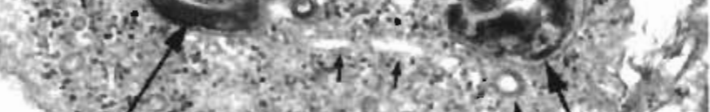
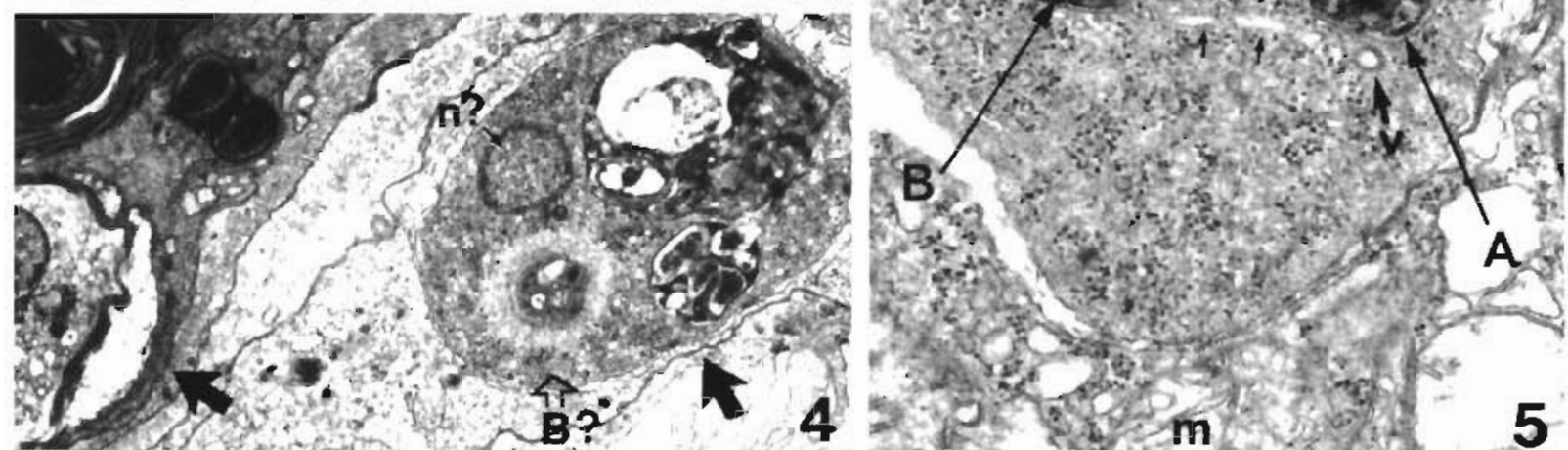

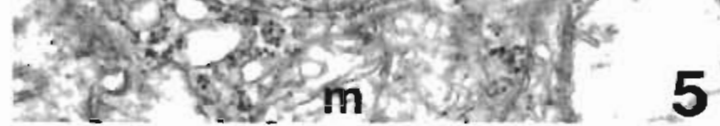
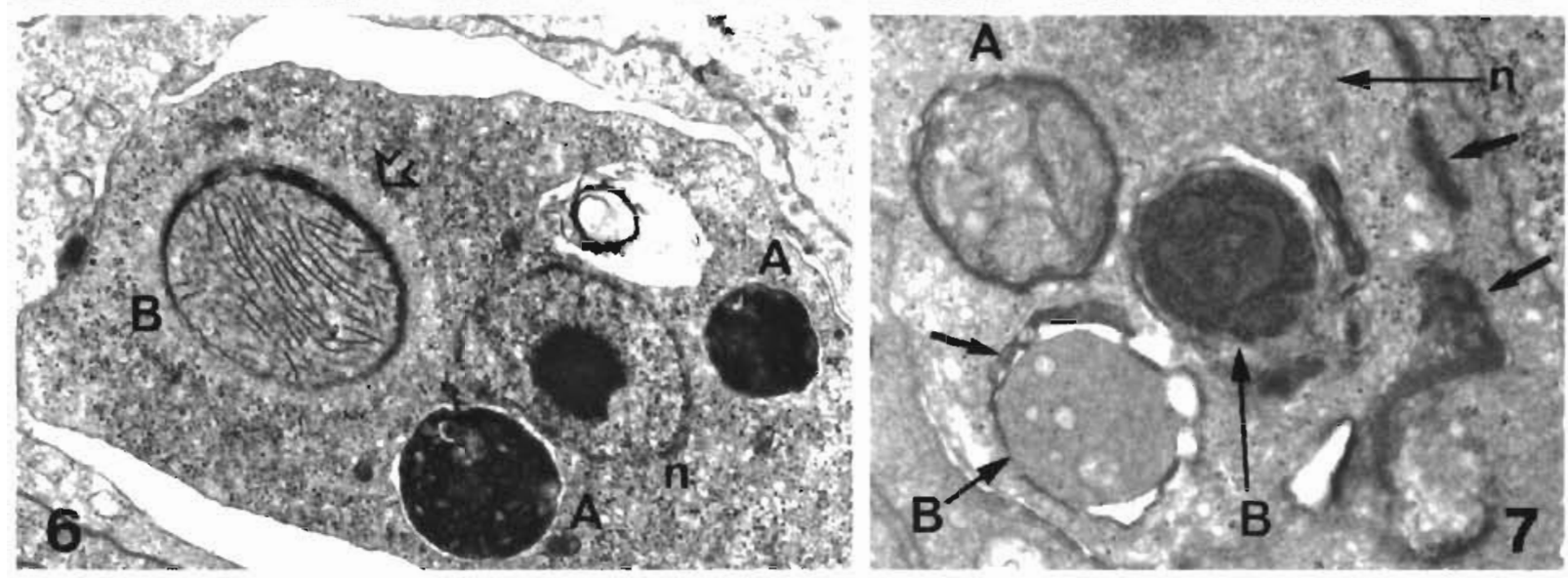


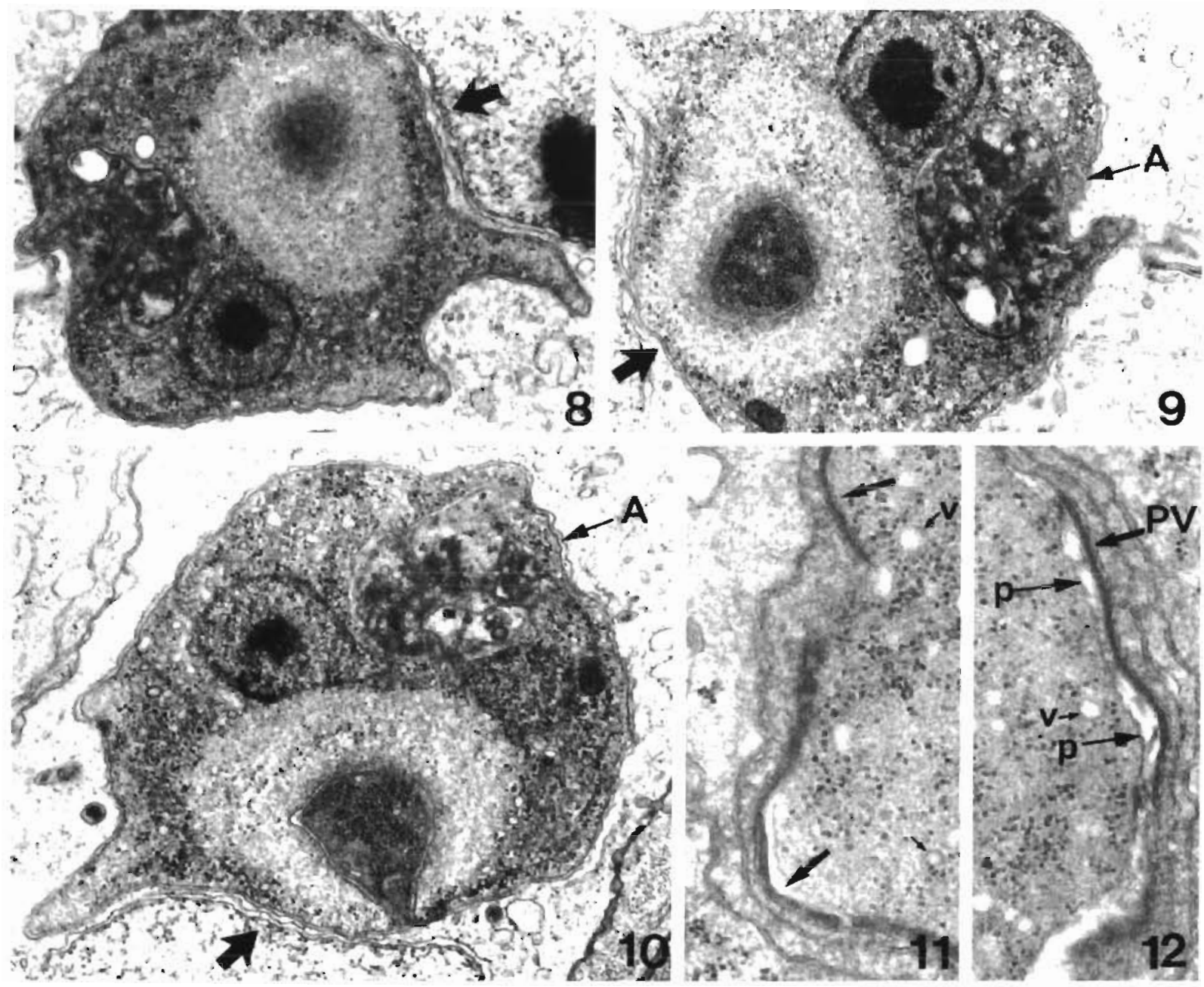

Figs. 8 to 10. Successive ultrathin sections of a D-organism showing progressive differentiation (bold arrow) from a ribosome-rich aggregate in a loose cytoplasmic halo (Fig. $8, \times 16575$ ) into a membrane bound 'segregated body' (Fig. 9, $\times 18190)$ which opens to the extenor of the organism's boundary (Fig. 10, ×19380), A. autolysosome-like bodies

Figs. 11 \& 12. Deposition of electron-dense matenal (bold arrows) in the parasitophorous vacuole (PV). p: plasmalemma; v: thickwalled vesicles $\times 36550$

dividing stages from the same salmon species described by Hedrick et al. (1989) look different. Simılarity with the oyster and clam parasite Perkunsus (syn. Dermocystidium marinus, Labyrnthomyxa marina; Perkins 1969) previously implied by McVicar \& Wooten (1980) is too remote, and is evident only in the character of the nucleus with its central nucleolus or endosome, the shape of the thick-walled divided spores, and possibly the presence of large inclusions and vacuolosomes (Perkins 1969, Azevedo 1989); however, in the latter, both mitochondria and lomosomes occur. Currently avalable fine-structural information still does not provide conclusive evidence as to the taxonomic nature of these organisms. The organisms from the goldfish have been regarded as hartmanellid amoebae (Voelker et al. 1977, Lom \& Dyková 1992).
There is, however, no real fine-structural evidence to support such an affiliation, if comparisons are made with avallable electron-microscopic images from a variety of free and parasitic amoebae (Vickerman 1962, Bowers \& Korn 1969, Lasman 1982, Visvesvara et al. 1993). Mitochondria were absent in the D-organIsms. Mitochondra of free amoebae during encystation may however become incorporated into the autolysosomes (Bowers \& Korn 1969). Nonetheless mitochondria were also absent from the organisms which are presented by Steinhagen et al. (1993) from infections which were apparently at their proliferative phase. Mitochondra as well as typical Golgi Apparati are lacking in Entamoeba histolitica which has been therefore regarded as a predecessor of true eukaryotes (Protoeukaryota or Archeozoa, see Bakker-Grunwald \& 
Wostmann 1993), possible affiliation with the so-called protoeukaryotes however needs further consideration.

The observed organisms, trapped among the host cells of the granulomatous tissue, seemed to be in a gradual process of degeneration. This may be inferred from the presence of autolysosome-like inclusions (earlier named autophagocytic vacuoles; Voelker et al. 1977 ) and the finding of extracellular organisms within a necrotic matrix. Such a situation could have some physiological analogy with the encystation process in amoebae, whereby defunct mitochondria of the Dorganisms could have become incorporated into the autolysosome-like inclusions.

The 'segregated bodies' are unique. Voelker et al. (1977) regarded them as autophagocytic vacuoles as well as the inclusions containing electron-dense substance. They are eventually seen displaced to the PV and could be undergoing a budding process reminiscent of secondary cell formation in myxosporeans (Lom \& Dyková 1992) or Marteilia (Desportes 1984). The development of a nucleus was, however, never traced in these bodies. Alternatively these bodies could have been phagosomes which, rather than being discharged into the PV (as seen in Fig. 10), originate through engulfment of pinched-off segments of host cytoplasm at the PV border.

Acknowledgement. This research was supported by a grant (no. 2763) from the National Council for Research and Development of the Ministry of Sciences and Art, Israel.

\section{LITERATURE CITED}

Azevedo C (1989) Fine structure of Perkinsus atlanticus n. sp. (Apicomplexa, Perkinsea) parasite of the clam Ruditapes decussatus from Portugal. J Protozool 75:627-635

Responsible Subject Editor: W. Körting, Hannover, Germany
Bakker-Grunwald T, Wostman C (1993) Entamoeba histolitica as a model for the primitive eukaryotic cell. Parasitol Today $9: 27-31$

Bowers B, Korn ED (1969) The fine structure of Acanthanoeba castellanii (NEFF strain). II Encystment. J Cell Biol 41: $786-805$

Desportes I (1984) The Paramyxea Levine 1979: an original example of evolution towards multicellularity. Orig Life 13:343-352

Hedrick RP, Fridman CS, Modin J (1989) Systemic infection in Atlantic salmon Salmo salar with a Dermocystidium-like species. Dis Aquat Org 7:171-177

Kovacs-Gayer E, Csaba G, Ratz F, Bekesi L, Szakolczai J (1986) Granulomatosis of common carp (Cyprinus carpio L.). Bull Eur Ass Fish Pathol 6:72-75

Landsberg JH, Paperna I (1992) Systemic granuloma in goldfish caused by a Dermocystidium-like aetiological agent. Dis Aquat Org 13:75-78

Lasman M (1982) The fine structure of Acanthamoeba astronyxis, with special emphasis on encystment. J Protozool 29:458-464

Lom J, Dyková I (1992) Protozoan parasites of fishes. Elsevier, Amsterdam

McVicar AH, Wooten R (1980) Disease in farmed juvenile Atlantic salmon caused by Dermocystidium sp. In: Ahne $W$ (ed) Fish diseases. Third COPRAQ Session. SpringerVerlag, Berlin, p 165-173

Perkins FO (1969) Ultrastructure of vegetative stages in Labyrinthomyxa marina (= Dermocystidium marinum), a commercially significant oyster pathogen. J Invertebr Pathol 13:199-222

Steinhagen D, Jendrysek S, Korting W (1993) Amöbiasis bei Goldfischen. Kleintierpraxis 38:469-474

Vickerman K (1962) Patterns of cellular organization in limax amoebae, an electron microscope study. Exp Cell Res 26: $497-519$

Visvesvara GS, Schuster FL, Martinez AJ (1993) Balamuthia mandrillaris, n. g., n. sp., agent of amebic meningoencephalitis in humans and other animals. J Euk Microbiol 40:504-514

Voelker FA, Anver MR, McKee AE, Cassey HW, Brenniman GR (1977) Amebiasis in goldfish. Vet Pathol 14:247-255

Manuscript first received: July 17, 1995

Revised version accepted: January 8, 1996 